\title{
Imputabilidade penal dos psicopatas à luz do código penal Brasileiro
}

\section{Criminal responsibility of psychophats in the light of the brazilian penal code}

\author{
Juliana Atanai Gonçalves Moura ${ }^{1}$; Fernanda Eloise Schmidt Ferreira Feguri²
}

\section{Resumo}

Justifica-se a escolha do presente tema, ante a polêmica na doutrina e na jurisprudência, quanto à forma que um psicopata vem sendo tratado perante o artigo $26 \S$ único do Código Penal Brasileiro e, também, explanar o porquê de tanta reincidência em crimes bárbaros. No início do trabalho, foi demonstrado o conceito de crime e as disciplinas que cercam o direito penal, seguido do conceito de psicopata, passando pela história, relatando alguns tipos de transtornos de personalidade e quando e como surgiu a origem da psicopatia e como as pessoas que possuíam este transtorno eram tratadas na antiguidade. Em seguida, foi explanado o que vem a ser a culpabilidade, de que forma se dá a sua aplicação, passando pela imputabilidade, inimputabilidade se atendo ao artigo $26 \S$ único do Código Penal Brasileiro. Seguindo-se a isto, chegou ao instituto da medida de segurança, através de seu conceito, pressupostos e modalidades, abrangendo a aplicação, prazo e cessação da periculosidade, cabendo ainda ressaltar sobre os laudos periciais. Por último, foram relatados casos concretos que envolvem pessoas que possuem um tipo de transtorno de personalidade, sendo descritos de forma sucinta de como eles são vistos perante a justiça e a sociedade. Encerrando o estudo, chega-se à conclusão de que tais indivíduos não sejam eles anistiados com o beneplácito da semi-imputabilidade, prevista no artigo 26 , $\S$ único do Código Penal Brasileiro. Pois o que se percebe, com a recente pesquisa, é que o benefício da imputabilidade penal diminuída, conferida a esses agentes que não têm plena capacidade mental, é injusta, pelo fato de que algumas pessoas podem ficar na cadeia por muito tempo, enquanto estes que recorrerem para a psiquiatria poderão estar fora dos estabelecimentos hospitalares, se for o caso, num prazo de três anos, pela benevolência das leis que os protegem. Com isso, endossa, o presente trabalho, que a prisão ou qualquer outra sanção penal é mais honesta, mais justa, menos discriminatória socialmente, que a sanção psiquiátrica.

Palavras-chave: Direito penal. Psicopata. Imputabilidade. Medida de Segurança. Semi-imputável. Internação. Prisão perpétua.

\begin{abstract}
Justifies the choice of this theme, before the controversy in doctrine and jurisprudence as to what a psychopath is being treated before Article $26 \S$ only the Brazilian Penal Code, and also explain why such barbaric crimes in recidivism. At the beginning of the work, it was demonstrated the concept of crime and the disciplines surrounding the criminal law, followed by the concept of a psychopathic, through history, reporting some types of personality disorders, and when and how did the origin of psychopath and how people who had this disorder were treated in the antiquity. It was then explained what becomes of guilt, how takes its implementation, trought accountability, nonimputability sticking to Article $26 \S$ only the Brazilian Penal Code. Following this came to the institute's measure of security, through its concept,
\end{abstract}

\footnotetext{
${ }^{1}$ Graduanda do Curso de Direito da Faculdade de Apucarana - FAP. Apucarana - Pr. Email: ju_moura20@hotmail.com

${ }^{2}$ Mestre e Doutoranda em Direito. Advogada atuante na Comarca de Apucarana-Pr. Docente da Faculdade de Apucarana - FAP. Apucarana - Pr. Email: fernanda.ferreira@fap.com.br
} 
assumptions and methods, including the application, term and termination of dangerousness being still emphasize on expert opinions. Finally, it was reported that cases involving people who have a type of personality disorder, being described succinctly as they are seen to justice and society. Concluding the study, one comes to the conclusion that such individuals are not they amnestied of the semi-liability provided for in Article 26, § only the Brazilian Penal Code Article 26, § only the Brazilian Penal Code. For what can be seen, with latest research is that the benefit of diminished criminal responsibility, given to those agents who do not have full mental unfair, the fact that some people can stay in jail for long as these recourse to psychiatry may be out of hospitals, if any, within three years, by the grace of the laws that protect them. Thus, endorse, this work, that the arrest or other criminal penalty is more honest, more fair, less socially discriminatory, that the sanction psychiatric.

Keywords: Criminal law - Psychopath. Psychopath - accountability. Security Measure - Semiattributable. Hospitalization. Life imprisonment.

\section{Introdução}

Numerosas são as ocorrências de crimes desumanos que atingem nossa sociedade, crimes cometidos com um grau elevado de muita crueldade, frieza, insensibilidade e manipulação. Em primeiro momento, serão analisados o direito penal e algumas das suas disciplinas complementares, passando pelo conceito de direito penal e crime, sendo abordados, também, criminologia legal e medicina legal.

Em seguida, expõe-se com vagar um estudo sobre psicopatias, no que tange à classificação dos transtornos da personalidade, englobando o conceito de psicopatas, suas classificações e sintomatologias, procurando, este trabalho, mostrar o que leva indivíduos a cometerem tamanhas barbáries e como o ordenamento jurídico brasileiro vem abordando.

Já dando continuidade, arguirá sobre a culpabilidade, aplicação da pena ao lado da imputabilidade e inimputabilidade. Enfatizando sobre as medidas de seguranças, seu conceito, juntamente com um estudo arraigado sobre seus pressupostos, modalidades, procedimentos, aplicações e prazos dos laudos de cessação da periculosidade.

Objetiva-se, com este trabalho, contribuir para o entendimento a respeito desse problema que, cada vez mais, é discutido nos tribunais e vem aumentando gradativamente na sociedade. Perante a controvérsia, surgem os mais variados entendimentos sobre qual ação penal melhor atende às necessidades da sociedade. Destarte, após análise dos argumentos defendidos por cada entendimento, chegar-se-á a um posicionamento. Entretanto, será indispensável considerar o texto da lei, precavendose para o não cometimento de injustiça com a vítima e, também, com o agressor, a fim de não causar danos insuportáveis no âmbito familiar e social.

\section{O Direito Penal, Crime e as Disciplinas Complementares}

Atualmente, depara-se com fatos que questionam o que vem a ser Direito Penal. Para Luiz Regis Prado (1997, p. 47)

o direito penal como sendo 'o pensamento jurídico moderno que adota o desígnio imediato e primordial do Direito Penal, é o amparo aos bens jurídicos essenciais ao indivíduo e à sociedade'. Trata- se de um direito voltado às normas emanadas do Poder Legislativo, com o intuito de conter transgressões, cominando através de suas sanções a proteção à coletividade. Já, para Victor Eduardo Rios Gonçalves, Direito Penal vem a ser um ramo do direito público que tem o intuito de definir as infrações penais, estabelecendo as penas e as medidas de segurança aplicáveis aos seus infratores. (apud GONÇALVES, 2003, p. 1)

Sendo de suma importância tal distinção. No mais, necessário se faz distinguir o direito penal objetivo do subjetivo, pois o primeiro refere-se a uma união de normas que estão em vigor no país, 
já o segundo trata-se do direito que o Estado tem de acoimar. Vale ressaltar sobre o Direito Penal Substantivo e o Adjetivo que, de acordo com Julio Fabbrini Mirabete, define-os como sendo:

Direito Penal substantivo (ou material), representado pelas normas que definem as figuras penais, estabelecendo sanções (códigos, leis etc.) e Direito Penal Adjetivo (ou formal) como sendo os que constituem preceitos de aplicação do direito substantivo e de organização judiciária (MIRABETE, 2001a, p. 26)

No que concerne ao crime, sua apreciação é essencialmente jurídica e cabe sobre dois aspectos que, para Julio Fabbrini Mirabete, "existe o aspecto formal e material, sendo que o primeiro vê o crime como sendo fato humano contrário à Lei." (MIRABETE, 2001-a, p. 95). Para Giusepppe Maggiore (1951, v. 1, p. 189), "Crime é qualquer ação legalmente punível”, pois, então, quando um agente age contrário a uma norma jurídica, logo ele está cometendo um crime. No segundo aspecto, ou seja, material, se faz "indagar as razões que levou o legislador a prever a punição dos autores de certos fatos e não de outros, critérios para distinção de ilícitos penais de outras condutas lesivas". Agora, no que tange as peculiaridades do crime sobre a aparência formal "se faz jus uma conduta positiva (ação em sentido estrito) ou negativa (omissão), sendo necessário que esta conduta seja típica e antijurídica" (MIRABETE, 2001a, p. 97). O artigo 30 do Código Penal fala das circunstâncias elementares.

No tocante ao crime doloso, existem três teorias: a da vontade, da representação e a do assentimento. Segundo Julio Fabbrini Mirabete (2001b, p. 139), a teoria da vontade é:

Age dolosamente quem pratica a ação consciente e voluntariamente, já a da representação afirma que o dolo é a simples previsão do resultado e, em última análise, na teoria do assentimento (consentimento), existe dolo, simplesmente quando o indivíduo consente em causar o resultado ao praticar a conduta.

Portanto, para que tenha o dolo, o agente tem que agir de forma consciente, para concorrer à prática de um resultado. O artigo 18, I, do Código
Penal, afirma o que vem a ser um crime doloso. Existem outras classificações de dolo, sendo elas: dolo direto (o agente quer o resultado); indireto ou indeterminado (o dolo não é preciso), podendo existir dolo alternativo (o indivíduo quer entre dois ou mais resultados) ou dolo eventual. Já, no que tange ao crime culposo, tem-se alguns elementos, sendo eles: a conduta, a inobservância do dever de cuidado objetivo, o resultado lesivo involuntário, a previsibilidade e a atipicidade. Existem, também, algumas modalidades de culpa: imprudência, negligência e imperícia. No que envolve as espécies, a culpa pode ser: consciente (o agente prevê o resultado), inconsciente (não prevê o resultado que é previsível), culpa própria (o agente não quer o resultado nem assume o risco de produzi-lo) e imprópria (o sujeito quer o resultado, mas sua vontade está viciada por um erro que poderia ter evitado), culpa presumida (ele é punido por determinação legal que presume a ocorrência dela). A culpa ainda pode ser, no que se refere ao seu grau: "grave, leve e levíssima"(MIRABETE, 2001b, p. 145-152). O artigo 18, II do Código Penal determina o que vem a ser crime culposo. Como exemplificado anteriormente, para que haja a distinção de um crime, é indispensável que exista perfeita adaptação do fato concreto ao tipo penal.

\section{Criminologia e Medicina Legal}

Sobre criminologia, é ela que analisa o criminoso, realizando estudo sobre sua personalidade, o crime por ele praticado e, também, sobre sua reintegração na sociedade. Para Newton Fernandes e Valter Fernandes, "a criminologia clínica se distingue da criminologia criminal que somente se volta para a perícia psiquiátrica e para a avaliação da responsabilidade delinquencial." (FERNANDES, 1995, p. 9), pois é ela quem realiza os exames, as perícias que identificam as descrições psicológicas distintivas do centro da personalidade criminosa, psicótica, para depois auxiliar o juiz na hora da 
sentença, para, poder, o mesmo, dizer se a sentença é absolutória imprópria. $\mathrm{O}$ exame criminológico é de suma importância, já que, através dele, podese chegar ao tipo de personalidade do delinquente, como a um psicopata. Para Odon R. Maranhão, "é através do exame criminológico que destaca a importância das informações jurídico-penais, afirmando, o mesmo, de que esse seja o primeiro item da observação criminológica."(MARANHÃO, 2000, p. 222), os exames morfológicos "não estão em uso mais, mas é nele que se avaliavam todas as parte do corpo humano" (MARANHÃO, 2000, p. 224), como cor de olhos, estatura, etc.. Trata-se da individualização do agente.

O exame psicológico tem como função descrever o perfil do agente analisado, independendo, muitas vezes, se existe uma suspeita de que ele possui ou não uma personalidade patológica mental (MARANHÃO, 2000, p. 225), para que, assim, possa se chegar a um indivíduo psicopata, seu grau de agressividade, através do "Psicodiagnóstico Miocinético (PMK) de Mira Y Lopes, podendo, também, ser utilizado testes para aferição de humor do agente, por meio da Tipologia de Sheldon e de Kretscheme." (PMK, 1993). No que tange ao exame psiquiátrico, "ele almeja alcançar os vários tipos de doenças mentais que existem nos agentes criminosos" (FERNANDES; FERNANDO, 1995, p. 230), é aqui que se identifica se o mesmo possui a personalidade psicótica, é ele que influencia a aplicação da pena, identificando se o indivíduo é imputável ou inimputável, que é o caso do psicopata.

No que fere a ser exame social e exame histórico, deve-se ter em mente que o primeiro busca "conhecer as condições que poderiam ter influenciado o agente em sua conduta antissocial, sendo analisado, também, o meio social em que o mesmo nasceu e viveu, por meio de um assistente social", já o segundo tem por finalidade "reconstruir o passado do delinquente, o estudo de sua conduta, antes e depois do ato criminoso praticado, se resistiu à prisão e assim por diante." Portanto, a criminologia, também, cuida "do tratamento dos delinquentes portadores de tais deficiências, moléstias psicológicas, para que, assim, os mesmos não voltem a delinqüir." (FERNANDES; FERNANDO, 1995, p. 238). Já a medicina legal em si, diagnostica o tipo de transtorno de personalidade que um doente mental, um psicopata possui. Para Odon Ramos Maranhão:

\begin{abstract}
A medicina legal tem grande influência na hora da aplicação de uma sentença e depois dela, pois é ela que diz ao Juiz se o agente possui ou não a personalidade psicótica e, também, é ela quem informa, através de seus laudos periciais, se o agente está tendo alguma reação positiva ao tratamento ambulatorial ou ao internamento aplicado como medida de segurança, um exemplo existente é a CID 10, pois é ela quem classifica o tipo de transtorno mental e comportamentos (MARANHÃO, 2000, p. 347).
\end{abstract}

Nesse ínterim, medicina legal, também, analisa as causas que levaram o indivíduo à morte, se o crime praticado contra o mesmo foi empreendido com violência "pois é através de um técnico que se realiza o exame mental." (MARANHÃO, 2000, p. 424), sendo de suma importância tal análise.

\section{Psicopatias (Transtornos de Personalidade)}

Existem indivíduos, envolventes, agradáveis aos outros, que se comportam de modo totalmente diferente com as pessoas de sua familiaridade. São pessoas explosivas, intolerantes, agressivas, que têm intenção de manipular seus demais. Indivíduos, portadores de uma perturbação de personalidade conhecida como Borderline, sendo que alguns tendem a serem desarmônicos dentro e fora do lar familiar, são conhecidos como sociopatas (CORDÁS, 1999, p. 23), hoje, com um grau muito elevado na nossa sociedade. A Organização Mundial de Saúde $^{3}$ relata que o distúrbio cognominado de personalidade Borderline está introduzido no capítulo dos transtornos de personalidade emocionalmente instável.

${ }^{3}$ ORGANIZAÇÃO MUNDIAL DA SAÚDE. CID. Disponível em: www.medicinanet.com.br/CID10/html. Acesso em: 10 dez. 2010. 
Tendo em conta que tal transtorno se subdivide em dois aspectos, sendo eles: o impulsivo e o borderline. Sendo o subtipo impulsivo versado como transtorno explosivo ou agressivo da personalidade. O CID. 10, ou seja, o Código Internacional de Doenças qualifica estes transtornos dentro da numeração 10 (UNIMED, 2005) ${ }^{4}$.

$\mathrm{O}$ indivíduo que possui o comportamento de personalidade borderline volta e meia se queixa de sentimentos incuráveis. Possui sempre capacidade de se envolver em relacionamentos intensos, mas de forma instável, os quais podem acarretar, nessas pessoas, repetidas crises emocionais (STONE, 1999, p. 34). Pois se relacionam muito fácil com sua vítima.

O Manual de Diagnóstico da Sociedade Americana de Psiquiatria- DSM. IV aponta que o predicado essencial do transtorno da personalidade borderline equivale a um padrão comportamental de volubilidade nos relacionamentos interpessoais, na autoimagem e nos afetos (BALLONE, 2011). Tendo uma exacerbada impulsividade, a qual se inicia na idade adulta e permanece vagamente, cujo atributo visto aqui tem relação com o comportamento.

O Transtorno que envolve a personalidade Borderline (BALLONE, 2011) é diagnosticado de forma predominante em seres femininos, que compõe cerca de $75 \%$ dos casos. No que se refere à prevalência, trata-se de cerca de $2 \%$ da sociedade em geral, incidindo em cerca de $10 \%$ dos pacientes de clínicas psiquiátricas e em cerca de $20 \%$ dos doentes psiquiátricos internados. Dentre os portadores de transtornos da personalidade em geral, o que prevalece, destes transtornos, oscilam entre $30 \%$ a $60 \%$.

Segundo alguns doutrinadores (STINGO et al., 1988, p. 88-99), "o indivíduo que possui o tipo de transtorno Borderline pode ser inimputável, em casos onde existiria um estado de inconsciência, especialmente por intoxicação, através de álcool ou drogas ou, até mesmo, devido à adulteração mórbida da capacidade mental."

\section{Classificação e Sintomatologia}

Psicopatas, indivíduos esses, também, conhecidos no seio da sociedade como sendo considerados sociopatas, personalidades antissociais, personalidades psicóticas, personalidades dissociais, personalidades amorais, entre outras (SILVA, 2008, p. 17), sendo abordado neste trabalho com o termo psicopata. Portanto, existem vários tipos de transtornos psicológicos, sendo alguns deles conhecidos como: "Personalidade introvertida (timidez), Personalidade Obsessivo-Compulsiva, Personalidade Esquizoide e Personalidade Narcisista" (BALLONE, 2011).

A personalidade introvertida, que se preocupa muito com que as outras pessoas pensam, ou seja, com a opinião dos demais, tem como definição a timidez sendo uma doença ou uma espécie doentia. Abordando o critério estatístico, um dos critérios utilizados para a análise médica carece ter em mente o seguinte: nem sempre, o comum é natural ou, ainda, nem sempre o extraordinário é patológico (STONE, 1999, p. 214). Contudo, tratar de uma conduta de personalidade que propicia prejuízo à população ou faz com que o introvertido se sinta rebaixado ou infeliz, acaba recebendo da psiquiatria uma atenção de doença, ainda que seja, sim, uma particularidade e não uma doença em si. Nessa abordagem, é evidente a descrição de personalidade, exclusivamente um aspecto; a forma pela qual o individuo contata o planeta à sua volta, a maneira pela qual a mesma interage com o mundo à sua volta, finalmente, o modo pelo qual o indivíduo se inclui com o objeto. Isso determinará os indivíduos ditos introvertidos e os extrovertidos (STONE, 1999, p. 215). Muito comuns na sociedade.

A Personalidade Obsessivo-Compulsiva referese ao agente que volta e meia parece ansioso ou demonstra algum tipo de medo. Fora isso, a pessoa, repetidas vezes, apresenta transtornos da personalidade concomitantes de diversos

\footnotetext{
${ }^{4}$ Código Internacional de Doença em sua unidade 10 cita estes tipos de transtornos de personalidade, caracterizando estas pessoas como seres que agem pelo impulso.
} 
agrupamentos de condutas 5 . O resultado deste tipo de transtorno produz uma determinação dos padrões de funcionamento do cidadão em grande prazo. Já as características particulares da personalidade têm a obrigação de ser presente no início da idade adulta. Contudo, as pessoas com Personalidade Esquizóide possuem um problema ao expressar sua raiva, mesmo quando atingidos pelos demais de forma direta, pois não possuem emoção, sua própria vida não segue um rumo correto. Pelo fato de não possuírem habilidades sociais e não terem desejo de ter experiências sexuais, tais pessoas não se relacionam muito e quase sempre não se casam. Individualmente, em resposta ao estresse que ocorre no dia a dia, os possuidores desse tipo de transtorno são capazes de vivenciar acontecimentos psicóticos muito breves ${ }^{6}$. Quanto aos indivíduos com o tipo de transtorno de Personalidade Narcisista, estes sentem a necessidade de mais admiração e carência de empatia, que principia no começo da idade adulta (CORDÁS, 1999, p. 78), ou seja, é nessa idade que se manifesta tal transtorno.

No entanto, o agente que possui este tipo de características de personalidade que atendem os critérios, para um ou mais transtornos de personalidade, além do narcisista, todos podem ser diagnosticados (CORDÁS, 1999, p. 45). Tem a aparência mais benéfica para a discriminação entre o transtorno da personalidade narcisista e os transtornos da personalidade histriônica, anti-social e Borderline, cujos caracteres de influência mútua são, concomitantemente, sedutores indiferentes e carentes (CORDÁS, 1999, p. 68). Porém, existem transtornos de personalidades que podem co-ocorrer com outros tipos de transtornos mentais.

\section{Da Culpabilidade e da Aplicação da Lei Penal}

No momento em que há uma lesão a um bem tutelado pela norma jurídica, existe um fator típico e antijurídico que envolve a conduta do agente que, para Rogério Greco, “juízo de censura, de reprovabilidade que se faz sobre a conduta típica e ilícita praticada pelo agente" (GRECO, 2008, p. 89), juízo este sobre a concepção da vontade do agente. Segundo Miguel Reale, culpabilidade quer dizer "reprova-se o indivíduo por ter escolhido de tal modo que, sendo-lhe plausível atuar de consonância com o direito, tem preferido agir opostamente ao exigido na lei” (REALE JUNIOR, 1998, p. 85-86). De acordo com Julio Fabbrini Mirabete, para que haja culpabilidade, se faz necessário: "Indagar se o agente quis o resultado (dolo) ou ao menos podia prever que esse evento iria ocorrer (culpa em sentido estrito), com isso se chegou à teoria psicológica da culpabilidade, pois ela reside numa ligação de natureza psíquica entre o sujeito e o fato criminoso. (MIRABETE, 2001-a, p. 196).

Já para o mesmo autor, existem elementos que averigua a culpabilidade, devendo, primeiro, saber se:

O agente tem capacidade psíquica que lhe permitia
ter consciência e vontade dentro do que se determina
autodeterminação, diante de suas condições psíquicas,
a antijuridicidade de sua conduta de adequar essa
conduta à sua compreensão, essa capacidade psíquica
denomina-se a imputabilidade (MIRABETE, 2001-a,
p. 196).

Destarte, dá para saber se o agente é inimputável, se possui transtorno de personalidade psicopática. Vale ressaltar os artigos $26,27,28 \S 1^{\circ}, 21,20, \S 1^{\circ}$, 22 primeira e segunda partes todos do Código Penal, são excludentes de culpabilidade.

\footnotetext{
${ }^{5}$ Traços de personalidade são padrões persistentes no modo de perceber, relacionar-se e pensar sobre o ambiente e sobre si mesmo, exibido em uma ampla faixa de contextos sociais e pessoais. Apenas quando são inflexíveis e mal-adaptativos e causam prejuízo funcional ou sofrimento subjetivo significativo, os traços de personalidade constituem transtornos da personalidade. (STONE, 1999, p. 214).

${ }^{6}$ Essas pessoas quase sempre reagem de forma passiva a circunstâncias diferentes e têm dificuldade ao responder adequadamente a acontecimentos muito importantes de suas vidas (STONE, 1999, p. 90).
} 
A teoria do delito, a partir do século XIX, teve seus primeiros indícios sobre o que vem a ser um delito, em sua acepção de crime como sendo açãotipicidade-antijuridicidade-culpabilidade. Von Liszt e Beling foram os pioneiros do sistema causalnaturalista, mas somente com Welzel é que o sistema passou a ser finalista. Mas somente três teorias tiveram ênfase, sendo elas: a causal, final e social. Neste ínterim, a teoria que houve diversas modificações foi "a teoria normativa". Houve diversas modificações no sistema anteriormente citado, principalmente, no que envolve o tipo penal e a culpa, pois, para que o infrator fosse punido, tinha que ter um algo mais, além de dolo e culpa. Precisava saber se as condições em que se deparava podiam determinar uma conduta, conforme o direito, passando a ser exigido: imputabilidade, dolo e culpa e exigibilidade da conduta diversa. Para a Teoria da Ação Final, houve uma modificação no sistema causal, passando a ser: imputabilidade, potencial consciência sobre a ilicitude do fato e exigibilidade de conduta diversa. Já a Teoria Social da Ação engloba aspectos do causalismo e do finalismo"(GRECO, 2008, p. 381394). Para que um indivíduo seja responsabilizado por um fato típico e ilícito, por ele atentado, "é preciso que ele seja imputável"(GRECO, 2008, p. 395), ou seja, ele deverá ter consciência do delito que está cometendo ou atentando.

\section{Da Imputabilidade e da Inimputabilidade}

Imputabilidade vem do latim "capacitas delictorum, que tem como significado atribuir culpa ou delito ao seu suposto autor." (BRASIL, 2011a), logo, imputar trata-se de uma qualidade para ser sujeito de uma imputação, como diz o artigo 26 do Código Penal Brasileiro: “Art. 26 - É isento de pena o agente que, por doença mental ou desenvolvimento mental incompleto ou retardado, era, ao tempo da ação ou da omissão, inteiramente incapaz de entender o caráter ilícito do fato ou de determinar-se de acordo com esse entendimento." (TOLEDO, 2011)
Para raciocinar sobre causas da culpa, devese levar em conta que a ligação psíquica entre o sujeito e o fato é feita mediante o conhecimento de culpabilidade e, por conseguinte, o da imputabilidade, necessita sempre empregar informações da ciência médica especializada na função psíquica (MIRABETE, 2001, p. 197). Desta forma, ao se aplicar noções das funções psíquicas à ética que se julgar da existência no mínimo de duas situações determinantes entre o sujeito e o ato; a situação voluntária (volitiva) e a situação involuntária (ou impulsiva casual). Induzindo para o direito a diferença entre essas duas formas de relacionamento dentre o sujeito e o objeto, deste modo, brotou a distinção jurídica entre dolo e culpa (CAPEZ, 2001, p. 90).

Para que exista o dolo, se faz necessário que três subsídios estejam preservados, sendo eles: a consciência do ato (psíquico), a vontade (psíquico) e o conhecimento da ilicitude (normativo). Para que haja a culpa, sem o dolo, tem que haver a ausência ou o prejuízo de um ou mais desses três elementos citados acima. Destarte, a culpa poderá existir, independentemente da consciência. Já no que diz ao dolo, não (MIRABETE, 2001-a, p. 34). Sendo assim, a culpa independe da consciência do indivíduo.

De tal modo, a não imputabilidade ou a inimputabilidade encontram-se presentes, quando não se pode atribuir ao sujeito à culpa e, evidentemente, ao dolo. Quase sempre, essa situação diz respeito ao agente que não tem condições de discriminar a natureza ilícita de uma ação, ou seja, não tem consciência completa do que está praticando ou não tem nenhum tipo de domínio sobre sua vontade (DELMATO, 2000, p. 50). Podese citar aqui o indivíduo que possui o transtorno de personalidade psicopática.

Destarte, a teoria que mais se estuda a intencionalidade da ação humana é chamada de Teoria Finalista da Ação (JESUS, 1996, p. 57). $\mathrm{Ou}$ melhor, o indivíduo tem o intuito, cogita, 
mentalmente, a buscar um fim para seu ato delituoso, fim este que faz parte da vida de um psicopata.

Sendo assim, o artigo 26 do Código Penal Brasileiro, no seu parágrafo único (BITENCOURT, 2008a, p. 107), depara-se com um caso de semiimputabilidade (FRANCO et al., 2001. p. 436.) ${ }^{7}$, pessoas que possuem uma redução na capacidade de compreensão ou vontade. No que diz respeito à personalidade psicopática, ela se encontra configurada dentro deste artigo, sendo que se encontra na lista das perturbações da saúde mental, pelas perturbações de conduta, anomalia psíquica que se revela de maneira violenta (MIRABETE, 2001-a, p. 213). Já o art. 98 (BITENCOURT, 2008a, p. 330), diz que a pena cominada ao mesmo será direcionada a tratamento clínico ou ambulatorial. Com a chegada da legislação nova, foi substituído o antigo sistema do dúplice binário, o qual se aplicava a pena reduzida somada com a medida de segurança, já com o advento da reforma em 1984, passou a entrar em vigor o sistema vicariante, que se aplica a pena reduzida, podendo ela ser substituída pelo tratamento ambulatorial ou medida de segurança (MIRABETE, 2001-a, p. 215) ${ }^{8}$, que ficará a cargo do juiz decidir qual a melhor medida a ser tomada na hora da aplicação da sentença absolutória.

Psicopatia trata-se de um tipo de transtorno "qualificado por atos antissociais permanentes" (sem consistir em sinônimo de criminalidade) e especialmente por uma incapacidade de adotar normas sociais em grandes aspectos do desenvolvimento da adolescência até a vida adulta. Quem possui este transtorno psicótico, não apresenta nenhum sinal de anormalidade mental, assim como, delírios, alucinações, tornando mais difícil a sua compreensão. Entender de uma forma mais abrangente o funcionamento dos psicopatas é um serviço de importância fundamental para a nossa humanidade, pois, o número de portadores deste tipo de transtorno aumenta de forma muito rápida e influi em todos os âmbitos do meio social, da medicina ao direito, da polícia ao mundo dos negócios (SABBATINI, 2010).

A decisão de uma sentença, em casos de semi-imputabilidade, será condenatória (JESUS, 1996, p. 98), a distinção entre inimputabilidade e responsabilidade diminuída, encontra-se já que no primeiro fato o sujeito é completamente incapaz de discernir o caráter ilícito do ato, não tendo, assim, aptidão intelectiva ou volitiva, já, no que se refere à capacidade diminuída, não suprime completamente sua capacidade intelectual ou volitiva. Neste fato, a culpabilidade não é afastada, mas a pena é diminuída, já que a responsabilidade estava diminuída (DELMANTO, 2000, p. 51), ficando a cargo do laudo médico atestar o grau de insanidade.

De acordo com Dr. Robert D. Hare (2009), psicopatia é o constructo clínico de grande relevância para com o sistema jurídico penal e as implicações do estudo deste transtorno são importantes, seja por sua relação com taxas de reincidência criminal, seja para seleção de tratamento apropriado e programas de reabilitação. A prevalência da psicopatia encontra-se em torno de $1 \%$ na população no âmbito geral e $15-20 \%$ na carcerária. Porém, apesar de sua baixa incidência na população em geral, são os responsáveis por $50 \%$ em média de delitos violentos cometidos nos Estados Unidos, sendo, deste modo, muito prejudicial à sociedade.

No que tange ao sistema carcerário brasileiro, não existem análises padronizadas para a avaliação da personalidade do aprisionado e meios que ajudem a prever o grau de reincidência criminal (CAPEZ, 2001, p. 258). Trata-se de um caso que vem prejudicando cada vez mais a população, pois, tais indivíduos saem de suas grades e cometem cada vez mais delitos, por causa dessa falha do sistema prisional.

\footnotetext{
${ }^{7}$ Dentre a higidez mental e a completa insanidade psíquica, tem uma zona medianeira na qual se situa a semi- imputabilidade que recebeu, no parágrafo único do artigo 26 , um tratamento normativo próprio.

${ }^{8}$ Em alguns casos, tem decidido que, reconhecido no laudo pericial à necessidade de isolamento por longo período ou definitivo, como na suposição de ser o agente portador de personalidade psicopática, deverá o Juiz, até mesmo por sua periculosidade, escolher pela substituição da pena por medida de segurança, para que se dê início ao tratamento necessário.
} 
Contudo, psicopatas têm um tipo de espécie de pobreza emocional, de sentimentos. São pessoas que possuem um grau elevado de inteligência e crueldade. Porém, segundo o neurologista Ricardo de Oliveira Souza, "Para um psicopata, atirar em uma pessoa e jogar fora um copo plástico são atos muito parecidos" (SOUZA, 2010), pois o mesmo não dá valor à vida de um ser humano.

É muito importante para o sistema jurídico, a distinção entre o criminoso comum e o criminoso psicopata, por causa da reincidência criminal, uma vez que o Código Penal Brasileiro admite a imputabilidade diminuída para as pessoas que não possuem a plena capacidade de determinação, pois, perante o artigo 26, § único, do Código Penal Brasileiro, a pessoa que não é capaz de se determinar de modo pleno, apesar de que o entendimento esteja resguardado, preenche a condição médicolegal de semi-imputabilidade, beneficiando assim o psicopata (BITENCOURT, 2008b, p. 107), ou melhor, a pessoa que não tem capacidade plena. Destarte, o psicopata encontra-se nos tipos de transtorno antissocial da personalidade como figura mais grave de manifestação. Personalidade esta que apresenta maiores números de reincidência criminal.

\section{Das Medidas de Segurança, Conceito, Aplicação, Pressupostos, Modalidades, Procedimentos, Aplicação, Prazo e Laudo de Cessação da Periculosidade}

Medida de Segurança vem a ser, segundo Luiz Regis Padro: "consequências jurídicas do delito, de caráter penal, orientadas por razões de prevenção especial" (PRADO, 2008, p. 624), ou seja, o agente que cometeu a conduta delituosa será punido de um ângulo diferenciado da pena. Para o inimputável, cabe o tratamento clínico ambulatorial ou internamento. $\mathrm{O}$ artigo $5^{\circ}$ da Carta Magna no seu inciso XXXIX, igualmente o artigo $1^{\circ}$ do Código Penal, falam do princípio da legalidade, em outro marco, o indivíduo tem o direito de ter ciência, de forma antecipada, da natureza da sanção penal que a ela foi submetida e a constância da mesma.

Os pressupostos e requisitos para a aplicação da medida de segurança, de acordo com Cesar Roberto Bitencourt (2008a), são: (a) prática de fato típico punível, sendo indispensável que o agente tenha cometido um ilícito típico, ou seja, que o delito praticado pelo mesmo seja punível, (b) periculosidade do agente, aqui o agente que cometeu a conduta ilícita tem que ser dotado de periculosidade, ou melhor, a periculosidade pode ser acentuada como um estado subjetivo mais ou menos duradouro de antissociabilidade, em outras palavras, tendo por base a conduta antissocial e anomalia psíquica de que o mesmo voltará a cometer mais delitos, sendo que o Código Penal expõe dois tipos de periculosidade: presumida (inimputáveis, psicopatas) e a real (semi-imputáveis e necessitar de algum tratamento psíquico), (c) Ausência de imputabilidade plena, pressuposto para a aplicação da medida de segurança, (BITENCOURT, 2008b, p. 704) ou melhor, se faz necessário analisar tais requisitos, antes do magistrado fazer jus à aplicação da medida de segurança em prol do agente.

Sobre a divisão entre pena e medida de segurança, vale ressaltar que o sistema dualista constitui de forma clara a divisão, pois este ponto de vista representa de fato muito mais que uma maneira conciliatória dentre as escolas partidárias do livre-arbítrio, clássicas, colocando o agente que possui doença mental à beira de qualquer sanção. No entanto, os positivistas, que negam a autonomia da vontade humana e dá valor à responsabilidade social, pelo fato de entenderem que as sanções penais necessitam atingir todas as pessoas que tenham cometido um delito (CORREA, 1999, p. 133), ou melhor, se o agente cometeu o delito, ele deve ser punido, a sanção penal tem que, de uma forma ou de outra, atingi-lo ele. Já o sistema Vicariante consiste na substituição da pena pela medida de segurança, havendo a partir daí duas classes de medida de segurança (a) a detentiva, que opta pela internação 
em clínica de custódia e tratamento psiquiátrico, pelo prazo mínimo entre um e três anos, passando a tornar-se indeterminado, perdurando a medida enquanto não sanar a periculosidade do agente, atestada por perícia medicinal, e (b) a restritiva, que consiste na sujeição do indivíduo a tratamento médico, cumprindo-lhe comparecer à clínica nos dias que lhe forem determinados pelo clínico, a fim de ser submetido à terapêutica prescrita (CORREA, 1999, p. 138), sendo este método adotado com muita rigidez pelos médicos.

Ao se referir aos psicopatas, esses indivíduos que fazem parte como já exposto, a semi-imputabilidade ou imputabilidade diminuída, por causa da doença mental ou desenvolvimento incompleto ou retardado. Contudo, o agente que faz jus à imputabilidade diminuída é responsável por ter certa noção do que faz, mas a sua responsabilidade é diminuída pelo fato de ter atuado com culpabilidade diminuída em decorrência das suas condições pessoais (CAPEZ, 2001, p. 269), ou seja, nos casos em que o indivíduo não era totalmente imputável, quando cometeu o delito. Destarte, a semi-imputabilidade não elimina a imputabilidade, como é o caso da inimputabilidade, de modo que o indivíduo será condenado pelo fato típico e ilícito que cometeu. Constatada a redução na capacidade de compreensão ou vontade, o magistrado terá duas alternativas: abatimento da pena de $1 / 3$ a $2 / 3$ ou impor medida de segurança, mesmo neste caso, a sentença continuará sendo condenatória (CAPEZ, 2004, p. 269), fica a cargo do juiz tal decisão. Destarte, o "agente inimputável, mesmo que tenha concorrido para a conduta delituosa, deverá ser absolvido, contudo, desde que seja aplicada tal medida de segurança, reconhecida como uma sentença absolutória imprópria" (TOURINHO, 2008, p. 207), ou melhor, deve-se ser imposta uma medida de segurança para este agente.

Existem algumas espécies de medida de segurança, é o que determina o artigo 96 do Código Penal:

Art. 96. As medidas de segurança são: I - Internação em hospital de custódia e tratamento psiquiátrico ou, à falta, em outro estabelecimento adequado;
II - sujeição a tratamento ambulatorial; Parágrafo único - Extinta a unibilidade, não se impõe medida de segurança nem subsiste a que tenha sido imposta (TOLEDO; WINDT; CESPEDES, 2011, p. 35.).

O artigo 97 do Código Penal relata: Se o agente for inimputável, o juiz determinará sua internação (art. 26). Se, todavia, o fato previsto como crime for punível com detenção, poderá o juiz submetêlo a tratamento ambulatorial" (TOLEDO; WINDT; CESPEDES, 2011). Assim sendo, o juiz tem a faculdade de optar por qual medida que adotará para o agente que cometeu a conduta típica (um psicopata), não se importando se a pena é de detenção ou reclusão. Para que seja possível oferecer uma denúncia a um agente inimputável, além de ter em mãos o laudo médico, deve-se ter conhecimento se a conduta delituosa praticada por ele era típica e antijurídica, pois, na ausência de um deles para a aplicação da culpabilidade, não há que se falar em infração penal de acordo com o art. 386, inciso V, do Código de Processo Penal (GRECO, 2008, p. 401). Deve-se levar em conta a conduta do agente, mesmo na fase inquisitória.

Nas ocorrências em que é comprovada a culpabilidade de um inimputável, ou seja, no caso de um indivíduo que possui o transtorno de personalidade psicopática, faz-se através de laudo clínico pericial, é impossível a condenação do agente, devido à imposição do art. 26 do Código Penal. Sendo que os artigos 171 e 173 da Lei 7.210/1984 Lei de Execução Penal referem-se à expedição de guia para a execução e por quem ela é extraída para dar cumprimento à medida de segurança. Para Luiz Regis Prado (PRADO, 2008, p. 629): “O prazo mínimo para a medida de segurança fixado por lei é de um a três anos (arts. $97, \S 1^{\circ}$, e $98 \mathrm{CP}$ ) [...], [...] Estabelece o $\S 1^{\circ}$ do artigo 97 do Código Penal que a internação e o tratamento ambulatorial serão por tempo indeterminado, perdurando enquanto não for verificada, através de pericia médica, a cessação da periculosidade.

Sendo que tal raciocínio tem levado grande discussão entre doutrinadores, no que diz respeito 
ao término desse prazo, pois se trata de um lapso temporal indeterminado e, sendo assim, fere o princípio constitucional que proíbe a prisão perpétua. No que se refere ao término da medida de segurança, Cesar Roberto Bitencourt relata:

\begin{abstract}
Devemos utilizar duas expressões; (a) suspensão e (b) extinção da medida de segurança, sendo que a suspensão estará condicionada ao transcurso de um ano de liberação ou desinternação, sem fato indicativo de persistência de periculosidade de acordo com o artigo $97, \S 3^{\circ}$ do Código Penal, somente se esse período percorrer in albis, será definitivamente extinta a medida suspensa ou revogada (BITENCOURT, 2008a, p. 706.)
\end{abstract}

Nos casos em que é demonstrado, através de perícia, a cessação da periculosidade, o juiz da execução decidirá pela revogação da medida de segurança com a desinternação ou liberação, de acordo com o artigo 178 da Lei de Execução Penal.

De acordo com o artigo 97 do Código Penal, mais precisamente em seu parágrafo $4^{\circ}$, traz à luz que "a qualquer fase do tratamento ambulatorial, poderá, o juiz, determinar a internação do agente, se essa providência for necessária para fins curativos". Isso acontece nos casos em que o juiz verifica que o tratamento que está sendo submetido ao agente não está tendo êxito para a sua cura, nestes casos, "poderá ele submeter o agente à internação em Hospital de Custódia e Tratamento Psiquiátrico ou outro lugar com dependências médicas adequadas" (GRECO, 2008, p. 683), ou melhor, caso o tratamento administrado pelo agente não está sendo positivo, o juiz poderá trocar a medida por uma mais eficaz. No que tange a extinção da punibilidade e medida de segurança, o artigo 96 (TOLEDO; WINDT; CESPEDES, 2011, p. 589) do Código Penal afirma: "extinta a punibilidade, não se impõe medida de segurança nem subsiste a que tenha sido imposta". Destarte, o agente que faz jus à medida de segurança deverá ser internado de acordo com o que é assegurado a eles por lei, ou seja, em estabelecimentos especializados para seu tratamento.

\section{Conclusão}

Diante do notório, a pesquisa empreendida neste trabalho, averigua que o benefício aplicado ao psicopata não versa à imparcialidade ou injustiça para com o indivíduo ou para com a população. Pois, o ordenamento jurídico brasileiro considera o psicopata como semi-imputável, tendo a faculdade de ser aplicada a medida de segurança ou ter ele uma diminuição, no que se refere à pena de $1 / 3$ a $2 / 3$, estando sujeito ao entendimento do juiz que, por meio de laudos periciais providos por peritos, carecerá propor a melhor repreensão adotada. Destarte, se faz necessário examinar se este é o mais perfeito caminho para se chegar a tão sonhada justiça. Claro que, para isso, o magistrado necessita de referências que o possam levar à sua conclusão e para que, assim, os psicopatas desprovidos de sanidade possam ser recuperados.

Injustiça! Esta engloba os delitos de grande repercussão social, sendo eles os crimes mais bárbaros que conglomeram a morte de inúmeras pessoas, verdadeiras chacinas. Em tais casos, na maioria das vezes, a defesa prefere pela solicitação de exame de sanidade mental. Sendo que, se o laudo for de que o indivíduo é incapaz ou parcialmente incapaz, como é o caso do psicopata, dos esquizofrênicos, o mesmo será absolvido e fará jus a uma medida de segurança que vai de 1 a 3 anos, sendo que cabe renovação anual para verificar a persistência da periculosidade. Trazendo para a prática, o que se verificou é que hospitais psiquiátricos custodiais e manicômios, que recebem esses indivíduos em sua estrutura, estão quase sempre superlotados, sendo suas vagas disputadas pelos magistrados. Diante disto, a pessoa que cometeu um delito monstruoso, mas foi considerada um psicopata para a medicina, ele poderá receber uma internação de, no máximo, três anos, e poderá estar fora, ser colocado em liberdade de uma clinica de internação com o fim desse período, nos casos em que fica constatado não possuir mais a periculosidade, que não colocará em risco a população. Sendo que isso não aconteceria, se não existisse a semiimputabilidade, quando ele passaria pelo menos uns 30 anos de sua vida em uma prisão. 
Partindo dessa premissa, o que se conclui, com a pesquisa realizada, é que o benefício da imputabilidade penal diminuída, conferida às pessoas que não possuem a plena capacidade mental, assertiva esta contida no parágrafo único, do artigo 26 do Código Penal Brasileiro, é injusta, pois, uma vez que algumas pessoas podem permanecer em uma prisão por mais tempo, outros indivíduos que recorrerem à psiquiatria poderão estar fora da dela, num prazo não superior a três anos, pela simples benignidade das leis que os têm protegido. Diante disto, percebe-se que a prisão ou alguma outra sanção penal é mais justa, bem menos discriminatória, socialmente, que a sanção proposta pela psiquiatria, pois nem mesmo seu lapso temporal de aplicação é determinado, sendo que, por este motivo de ser indeterminada, fere a Constituição federal, no que diz respeito à vedação de prisão perpétua, pois, assim como a pena a medida de segurança, não poderia ultrapassar o limite culminante de 30 anos.

Chegou-se à conclusão de que pouco se pode perpetrar para mudar o jeito de ser de um psicopata, não têm como mudar uma coisa que não tem cura. Destarte, já que a medida de segurança, também, além de "punir", tem caráter de cura e ressocialização e isso não acontece com tais seres psicóticos, todos devem ser julgados pelos atos, crimes que atentaram, cometeram, para não causarem insegurança a eles próprios e para a sociedade.

\section{Referências}

BITENCOURT, C. R. Tratado de direito penal. 13. ed. São Paulo: Saraiva, 2008a.

Código penal comentado. 13. ed. São Paulo: Saraiva, 2008b.

BALLONE, G. J. Personalidade borderline. Disponível em: <www.psiqweb.med.br/site>. Acesso em: 16 abr. 2011.

BRASIL. Imputabilidade. Disponível em: <www. direitonet.com.br/doutrina/textos/>. Acesso em: 7 fev. 2011a.
. Código Penal. Decreto-lei $n^{\circ} 2.848$, de 7 de

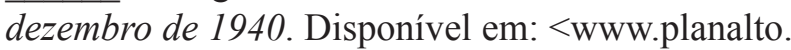
gov.br/ccivil_03/Decreto-Lei/De12848.htm>. Acesso em: 5 jan. 2011 b.

Código de Processo Penal. Decreto lei $n^{\circ} 3.689$, de 3 de outubro de 1941. Disponível em: $<$ http://www.planalto.gov.br/ccivil_03/DecretoLei/Del3689.htm>. Acesso em: 28 de abr. 2011c.

- Constituição (1988). Constituição da República Federativa do Brasil de 1988. Disponível em: $\quad<\mathrm{http} / /$ www.planalto.gov.br/ccivil_03/ Constituicao/Constituicao.htm>. Acesso em: 12 abr. 2011d.

CAPEZ, F. Direito penal: parte geral. São Paulo: Saraiva, 2001.

. Direito penal: parte especial. São Paulo: Saraiva, 2004.

CORDÁS, T. Distimia do mau humor. Porto Alegre: Artes, 1999.

CORRÊA, M. O doente mental e o direito. São Paulo: Iglu, 1999.

DELMATO, C. Código penal comentado. Rio de Janeiro: Renovar, 2000.

FERNANDES, F. V. Direito penal. São Paulo: Revista dos Tribunais, 1995.

FRANCO, A. S.; PANZERI, A. P.; DEZEM, G. M.; DIAS, J. A.; NINNO, J.; SILVA JUNIOR, J.; BELLOQUE, J. G.; BETANHO, L. C.; BÁRTOLI, M. O.; ZILLI, M. A. C.; MOURA, M. T. R.; GIMENES, M. C. C. S.; KURIKI, P. Ca.; FELTRIN, S. O.; SILVA, T. A. D.; STOCO, R. Código penal e sua interpretação jurisprudencial. 7. ed. São Paulo: Revista dos Tribunais, 2001.

GONÇALVES, L. C. S. Direito penal: parte geral. 7. ed. São Paulo: Saraiva, 2003.

GRECO, R. Curso de direito penal: parte geral. 10. ed. Rio de Janeiro: Impetus, 2008.

HARE, R. Psicopata no divã. Revista Veja, São Paulo, 1 abr. 2009. Disponível em: <http://veja. abril.com.br/010409/entrevista.shtml > . Acesso em: 22 out. 2010.

JESUS, D. E. Código penal anotado. São Paulo: Saraiva, 1996. 
MAGGIORE, G. Diritto penale. 5. ed. Itália: N. Zanelli, 1951. v. 1.

MARANHÃO, R. O. Curso básico de medicina legal. 8. ed. São Paulo: Malheiros, 2000.

MIRABETE, J. F. Manual de direito penal: parte geral. São Paulo: Atlas, 2001a.

. Código penal interpretado. São Paulo:

Atlas, $2001 b$.

ORGANIZAÇÃO MUNDIAL DA SAÚDE. CID.

Disponível em: www.medicinanet.com.br/CID10/ html. Acesso em: 10 dez. 2010.

PMK - Psicodiagnóstico miocinético. Journal of psychiatry research. 1993. Disponível em: <www./ psychiatry.res/content/view/230/93/>. Acesso em: 13 jun. 2010.

PRADO, L. R. Curso de direito penal brasileiro: parte geral: arts. $1^{\mathrm{o}}$ a 120 . 8. ed. São Paulo: RT, 2008.

. Bem juridico-penal e constituição. 2. ed. São Paulo: Revista dos Tribunais, 1997.

REALE JÚNIOR, M. Teoria do delito. São Paulo: RT, 1998.

SABBATINI, R. Doenças. Brain e mind eletronic magazine on neuroscience. Disponível em: <www. cerebromente.org.br/no7/doenças/index/html>. Acesso em: 22 jun. 2010.

SILVA, A. B. B. Mentes perigosas: o psicopata mora ao lado. Rio de Janeiro: Objetiva, 2008.

SOUZA, O. Psicopatas: o mal não existe. Disponível em: $<$ http://psicopatiapenal.blogspot. com/2010/10/criminosos-psicopata-o-que-cienciaja.html>. Acesso em: 21 mar. 2010.

STINGO, N. R. Manual de métodos cientificos. Buenos Aires: Eumens, 1988.

STONE, M. A cura da mente: a história da psiquiatria da antiguidade até o presente. Porto Alegre: Artmed, 1999.

TOLEDO, A. L.; WINDT, M. C. V. S.; CÉSPEDES, L. Vade mecum. 11. ed. São Paulo: Saraiva, 2011.

TOURINHO, F. C. F. Processo penal. 30. ed. São Paulo: Saraiva, 2008.

UNIMED. Consulta CID 10. 2005. Disponível em: <www.unimedcg.com.br/unimed2005/cid10.html>. Acesso em: 26 jul. 2011.

UNIVERSIDADE FEDERAL DE PELOTAS. $A$ psicanálise de Sigmund Freud. Disponível em: $<$ www.ufpel.edu.br/isp/dissertativo/revista/27-289-pdf>. Acesso em: 25 abr. 2010. 
